\title{
Melatonin alleviates photoinhibition in cucumber seedlings by modulating partitioning of absorbed excitation energy in photosystem III
}

\author{
H.L. ZHAO ${ }^{1,2,3,+} \mathbb{D}$, Y.P. WANG ${ }^{1,+*}\left(\mathbb{D}\right.$, K. GAO $^{1,2}$, Y. ZHANG $^{1,2,3} \mathbb{D}$, Y. SHI ${ }^{1,2,3} \mathbb{D}$, and Y.X. MIAO ${ }^{1,2,3}$ \\ ${ }^{1}$ College of Horticulture, Shanxi Agricultural University, Taigu, 030801, Shanxi, P.R. China \\ ${ }^{2}$ Shanxi protected vegetable quality improvement and Synergetic Innovation Center, \\ Taigu, 030801, Shanxi, P.R. China \\ ${ }^{3}$ Shanxi Key Laboratory of Facility Horticulture, Taigu, 030801,Shanxi, P.R. China
}

*Corresponding author: E-mail: yupinghigh@126.com

\begin{abstract}
The aim of this study was to evaluate the effects of melatonin on photoinhibition under chilling stress in cucumber seedlings and to inquire into any mechanisms of mitigation. Under chilling stress, the net photosynthetic rate declined dramatically but the decline was significantly mitigated by irrigation with a melatonin solution. Possible mechanisms for this mitigation are that melatonin accelerates xanthophyll de-epoxidation by upregulating the transcription of the violaxanthin de-epoxidase gene $(C s V D E)$ and down-regulating that of the zeaxanthin cyclase gene $(C s Z E)$ during chilling. There was also a rise in non-photochemical quenching (NPQ) if seedlings were pretreated with melatonin before chilling. The efficient operation of the xanthophyll cycle helped consume excessive excitation energy in photosystem (PS) II and so protected the photosynthetic system. Melatonin also modulated the partitioning of absorbed excitation energy in PS II as evidenced by alleviation of the decrease in quantum yield of photochemical energy conversion in PS II under chilling stress, by alleviation of the rise in quantum yield of non-regulated, non-photochemical energy loss in PS II and by increasing the regulated non-photochemical energy loss in PS II. This study presents a new understanding of the mechanisms through which melatonin mitigates photoinhibition by modulating the partitioning of absorption energy in PS II based on the xanthophyll cycle.
\end{abstract}

Keywords: chilling, Cucumis sativus, excitation energy, melatonin, photoinhibition, xanthophyll cycle.

\section{Introduction}

Low temperatures are one of the most significant abiotic factors limiting crop growth and development with increasing losses in the agricultural sector resulting from early frosts in the fall, freezing temperatures in the winter, and sudden cold spells in the late spring (Hu et al. 2010, Cooper et al. 2018, Wang et al. 2019b). Sudden chilling causes a number of serious metabolic disorders in plants, with one of the most significant being a decrease in the rate of photosynthesis. Even if more suitable temperatures prevail immediately after a chilling event, it still takes

$\overline{\text { Received }} 11$ October 2020, last revision 7 June 2021, accepted 30 June 2021.

Abbreviations: A - Antheraxanthin; Cd - cadmium; CsVDE - violaxanthin de-epoxidase gene; CsZE - zeaxanthin cyclase gene; $\mathrm{F}_{\mathrm{m}}$ - maximum fluorescence; $\mathrm{F}_{\mathrm{m}}{ }^{\prime}$ - maximum fluorescence under light; $\mathrm{F}_{\mathrm{o}}$ - initial fluorescence; $\mathrm{F}_{\mathrm{o}}{ }^{\prime}$ - initial fluorescence under light; $\mathrm{F}_{\mathrm{s}}$ - steady fluorescence under light; $\mathrm{F}_{\mathrm{v}} / \mathrm{F}_{\mathrm{m}}$ - maximum quantum yield of PSII photochemistry; NPQ - non-photochemical quenching; PAs - polyamines; $\mathrm{P}_{\mathrm{N}}$ - net photosynthesis rate; qP - photochemical quenching; ROS - reactive oxygen species; Spd - spermidine; V - Violaxanthin; Y(II) - quantum yield of photochemical energy conversion in PSII; Y(NO) - quantum yield of non-regulated nonphotochemical energy loss in PS II; Y(NPQ) - quantum yield of non-regulated non-photochemical energy loss in PSII; Z - Zeaxanthin. Acknowledgements: This research was supported by the Shanxi Province Applied basic Research Program [201801D221304], the National Key R\&D Program of China (2019YFD1001900), the Shanxi Province Key R\&D Plan [201703D211001-04-03], the Outstanding Doctor Founding Award of Shanxi Province [SXYBKY201719], the Science and Technology Innovation Fund of Shanxi Agricultural University [2017YJ44], and the Postgraduate Education Innovation Project of Shanxi Province [2020BY049].

+These authors contributed equally.

Conflict of interest: The authors declare that they have no conflict of interest. 
a long time for the photosynthetic rate to return to normal (Hu et al. 2010, Pu et al. 2021). The decline in photosynthetic rate causes a series of chain reactions. The first is a decline in water-use efficiency due to simultaneous excessive water loss and wilting of plants under chilling stress (Zhang et al. 2015). The reduction in photosynthesis reduces the availability of assimilates, which reduces the energy supply and also lowers the water uptake and transport capacities of the roots (Tuzet et al. 2003, Gan et al. 2019). Plant water deficit is further exacerbated as stomatal regulation is impaired. Photosynthetic rate is normally closely related to transpiration rate but, after a chill event, transpiration rate does not decline with a photosynthetic rate in a coordinated manner (López-Bernal et al. 2015). Also, because mineral elements are dissolved in the xylem water and thus transported within the plant with the movement of water, the upsetting of plant water transport inevitably also upsets plant mineral transport (Arms et al. 2015). This further exacerbates the disruption of the plant's physiology and metabolism. Therefore, alleviating chilling damage to the photosynthetic system is an important element of reducing the wider effects of chilling stress in plants.

Chloroplasts are the organelles of photosynthesis, and the perception of low temperatures in chloroplasts begins with the chloroplast membrane (Heidarvand and Amiri 2010). Temperature drops change the characteristics of all biofilms, including those of the photosynthetic system. This is manifested mainly in a series of changes, including a reduction in membrane lipid fluidity, in membrane elasticity, and a decline in the activities of the $\mathrm{H}^{+}$-ATPase and other membrane-bound enzymes (Kasamo et al. 1992). These changes in the plasma membrane system, lead to further ultrastructural changes in the photosynthetic apparatus. Thus, the chloroplast begins to expand and change from a typical oval shape to a more spherical one, the number of starch grains increases, chloroplast volume gradually increases, and the arrangement of the grana lamellae and matrix lamellae becomes looser and less ordered. Some matrix lamellae become more diffuse or disappear altogether (Zhao et al. 2016). Chilling damage to photosystem structure inevitably decreases the photosynthetic capacity of plants. Moreover, a decline in ambient temperatures also leads to reduced stomatal opening, a reduction in the activities of key enzymes in the Calvin cycle (including Rubisco), and a reduction in the photosynthetic dark reaction rate (Allen and Ort 2001). In this event, even low irradiance can cause photoinhibition, as the excess radiation energy entering the photosynthetic system cannot be utilized in the photosynthetic dark reaction. Hence, a significant proportion of the excited electrons enter the pseudo-ring electron transport pathway, where they induce the production of reactive oxygen species (ROS) and trigger oxidative stress (Zhang et al. 2011, Siddiqui et al. 2020).

A previous study has shown that melatonin can suppress this alternative electron flux and thus inhibit the overproduction of ROS by controlling photosynthesis electron flux under chilling conditions (Zhao et al. 2016). Melatonin helps maintain the normal operation of PS II not only under chilling but also under other abiotic stresses. Drought stress research shows that melatonin enhances osmotic regulation and the activities of antioxidative enzymes to offset the decline in photosynthesis (Zou et al. 2019). Under water stress, the application of melatonin can delay chlorophyll degradation in cucumber seedlings, with similar findings also reported for apple trees under drought stress (Wang et al. 2012, Zhang et al. 2012). Photoinhibition caused by cadmium phytotoxicity can be also alleviated by melatonin, with melatonin applications not only promoting $\mathrm{Cd}$ accumulation in the cell walls and vacuoles, but also accelerating ROS scavenging (Kaya et al. 2019, Wang et al. 2019a). Although considerable progress has been made in the study of the roles of melatonin in alleviating photoinhibition, little is known of the role of melatonin in adjusting for the surplus excitation energy in PS II.

Previous studies have shown that melatonin applications can affect the expression of stress-related transcription factor csZat12 and also the metabolism of polyamines (PAs) in cucumber seedlings (Zhao et al. 2017). In addition, spermidine (Spd) can enhance the xanthophyll cycle to protect photosynthetic apparatus from salt stress by dissipating excess radiation energy $(\mathrm{Hu}$ et al. 2014). It is speculated that melatonin may also play a stress-resistance role by regulating the xanthophyll cycle and then adjusting the distribution of radiation energy in photosynthetic organs under chilling stress conditions.

Cucumber is an important horticulture crop in many countries, needs to be planted all year-round to meet market demand. However, even when grown in a greenhouse, chilling stress, particularly under daytime conditions, is a major factor affecting cucumber production in winter. Therefore, further exploration of the melatonin-mediated alleviation of chilling stress in cucumber seedlings is important both from theoretical and practical points of view. It is worth clarifying whether photoinhibition in cucumber seedlings can be alleviated by melatonin under chilling stress conditions. In addition to exploring the functions of melatonin in mediating the allocation and utilization of absorbed energy in PS II, we also explore the mechanism through which melatonin regulates the xanthophyll cycle.

\section{Materials and methods}

Plants and treatments: Seeds of cucumber (Cucumis sativus L.) were soaked in warm water and germinated in the dark at $27{ }^{\circ} \mathrm{C}$. After germination, seeds were sown in a substrate composed of peat, Vermiculite, and Perlite $(3: 1: 1, \mathrm{v} / \mathrm{v} / \mathrm{v})$ and grown at day/night temperatures of $28 / 18{ }^{\circ} \mathrm{C}$, a 12 -h photoperiod, relative humidity of $75 \%$, and a photon flux density (PFD) of $300 \mu \mathrm{mol} \mathrm{m} \mathrm{m}^{-2} \mathrm{~s}^{-1}$ in a plant growth chamber. When the cucumber seedlings grew to two true leaves, the cucumber seedlings were supplied with 0 and $200 \mu \mathrm{M}$ melatonin in irrigation water. After $6 \mathrm{~d}$, half the seedlings in each group were transferred to a growth chamber for $8 \mathrm{~d}$, in which the temperature was set to $15 / 8{ }^{\circ} \mathrm{C}$ (day/night). The remainder continued to 
grow at the original temperature. This created four groups of plants: 1) control: seedlings irrigated with water and grown under normal temperatures for the whole period; 2) control+melatonin: seedlings irrigated with melatonin solution and grown under normal temperatures for the whole period; 3) chilling: seedlings irrigated with water and grown under normal temperatures for the first $6 \mathrm{~d}$ and then under chilling temperatures for the next $8 \mathrm{~d}$; 4) chilling+melatonin: seedlings irrigated with melatonin solution and grown under normal temperatures for the first $6 \mathrm{~d}$ and then under chilling temperatures for the next $8 \mathrm{~d}$.

Measurement of morphological parameters and photosynthetic rate: Eight days after the start of chilling, plant heights were measured with a ruler and stem diameters with a vernier caliper. To examine whether melatonin alleviated photoinhibition caused by chilling, we measured leaf net photosynthetic rate $\left(\mathrm{P}_{\mathrm{N}}\right)$ between 9:00 to 11:00, on days 2 and 6 of chilling using an LI-6400XT portable photosynthesis system (LI-COR, Lincoln, NE, USA) incorporating a 6400-08 leaf chamber. The PFD was maintained at $300 \mu \mathrm{mol} \mathrm{m}{ }^{-2} \mathrm{~s}^{-1}$ and the $\mathrm{CO}_{2}$ concentration at $350 \mu \mathrm{mol} \mathrm{m} \mathrm{m}^{-2} \mathrm{~s}^{-1}$.

Monitoring of chlorophyll fluorescence: After a full night of dark adaptation, the initial fluorescence $\left(F_{0}\right)$ and the maximum fluorescence $\left(\mathrm{F}_{\mathrm{m}}\right)$ were measured using a PAM-2500 chlorophyll fluorimeter (Walz, Effeltrich, Germany). After adaption at PFD of $300 \mu \mathrm{mol} \mathrm{m} \mathrm{m}^{-2} \mathrm{~s}^{-1}$, initial fluorescence $\left(\mathrm{F}_{\mathrm{o}}{ }^{\prime}\right)$, steady fluorescence under irradiance $\left(\mathrm{F}_{\mathrm{s}}\right)$, and maximum fluorescence under irradiance $\left(\mathrm{F}_{\mathrm{m}}\right)$ were measured. Fluorescence parameters were calculated as follows: the maximum quantum yield of PS II photochemistry, $F_{v} / F_{m}=\left(F_{m}-F_{o}\right) / F_{m}$; photochemical quenching, $\mathrm{qP}=\left(\mathrm{F}_{\mathrm{m}}{ }^{\prime}-\mathrm{F}_{\mathrm{s}}\right) /\left(\mathrm{F}_{\mathrm{m}}{ }^{\prime}-\mathrm{F}_{\mathrm{o}}\right)$; nonphotochemical quenching, $\mathrm{NPQ}=\left(\mathrm{F}_{\mathrm{m}}-\mathrm{F}_{\mathrm{m}}\right) / \mathrm{F}_{\mathrm{m}}$; quantum yield of photochemical energy conversion in PS II, Y(II) = $\left(\mathrm{F}_{\mathrm{m}}{ }^{\prime}-\mathrm{F}_{\mathrm{s}}\right) / \mathrm{F}_{\mathrm{m}}$; quantum yield of regulated non-photochemical energy loss in PS II, $\mathrm{Y}(\mathrm{NPQ})=\mathrm{F}_{\mathrm{s}} / \mathrm{F}_{\mathrm{m}}{ }^{\prime}-\mathrm{F}_{\mathrm{s}} / \mathrm{F}_{\mathrm{m}}$; quantum yield of non-regulated non-photochemical energy loss in PS II, $\mathrm{Y}(\mathrm{NO})=\mathrm{F}_{\mathrm{s}} / \mathrm{F}_{\mathrm{m}}$ (Baker 2008, Klughammer and Schreiber 2008).

Pigments in xanthophyll cycle isolation, identification, and analysis: Using a hole punch (inner diameter $1 \mathrm{~cm}$ ), 18 leaf discs were taken at one time and placed in a mortar. After grinding to a powder in liquid nitrogen, the sample was ground for $2 \sim 3$ min with $4 \mathrm{~cm}^{3} 85 \%(\mathrm{v} / \mathrm{v})$ acetone and $0,05 \mathrm{~g} \mathrm{CaCO}_{3}$. Then, acetone $\left(1 \mathrm{~cm}^{3} 100 \%\right)$ was added and samples were homogenized for $1 \mathrm{~min}$. After extracting on ice for $15 \mathrm{~min}$, the mixture was centrifuged at $15000 \mathrm{~g}$ for $5 \mathrm{~min}$. The supernatant was analyzed by HPLC after passing through a $0.45 \mu \mathrm{m}$ syringe filter (Hu et al. 2014).

RNA isolation and quantitative real-time PCR: With the actin gene as the internal reference, the primers (Table 1 Suppl.) designed by Primer 6 were used to analyze the relative expression of genes involved in the xanthophyll cycle. RNA isolation, reverse-transcription, and quantitative real-time PCR were performed as previously described (Zhao et al. 2016).

Statistical analyses: All data were statistically analyzed with statistical software Spass (version 20.0, IBM Institute, USA). The data are presented as means \pm SDs of at least three duplicated samples. Differences were compared using Duncan's multiple range test $(P<0.05)$.

\section{Results}

Eight days of chilling significantly inhibited the growth of cucumber seedlings as evidenced by morphological parameters: the height and stem diameter of chilled plants were only 68.9 and $75.9 \%$ of control plants, respectively (Fig. 1). The melatonin treatment reduced the inhibition of growth. Compared with chilling (no melatonin), the height and stem diameter of seedlings with melatonin pretreatment were higher by 16.6 and $11.8 \%$, respectively. Compared with un-chilled leaves, the net photosynthetic rate of chilled leaves decreased by $37.3 \%$ on day 2 and $77.1 \%$ on day 6 (Fig. 2). However, the application of melatonin significantly reduced this decline. Compared

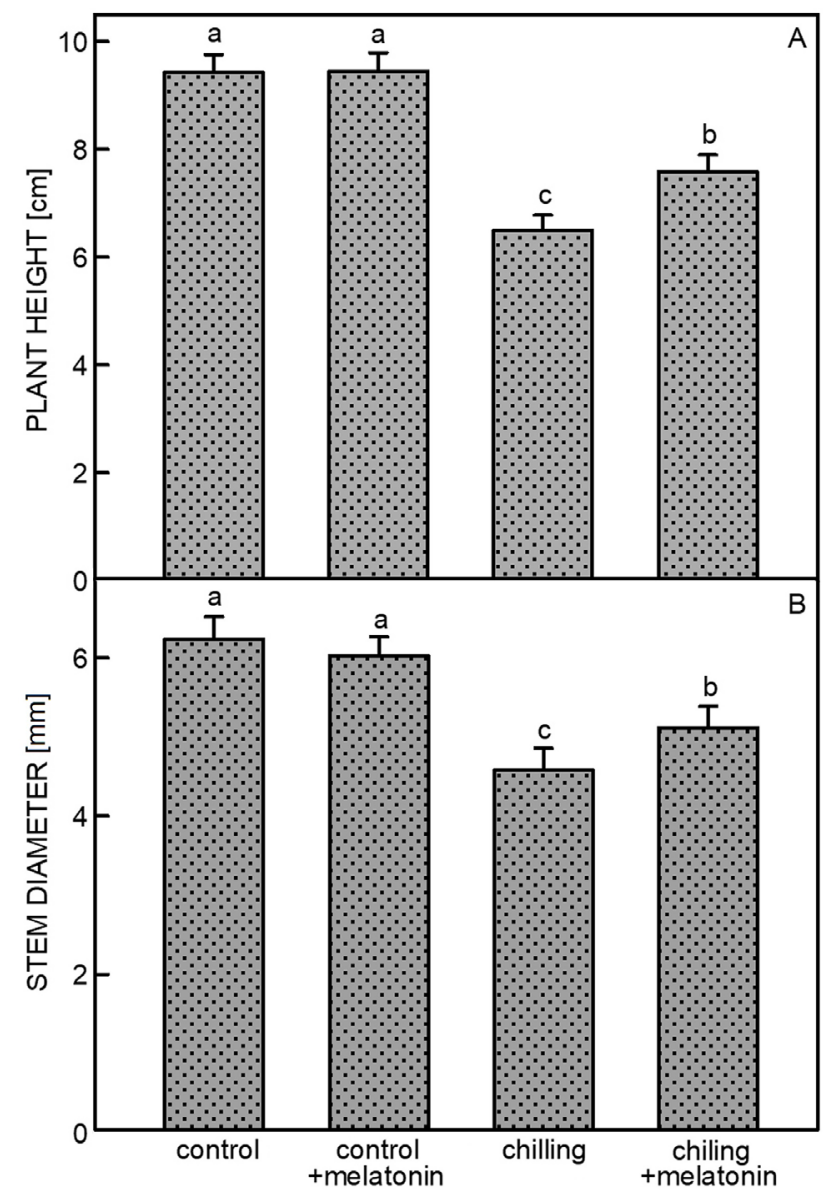

Fig. 1. Effects of exogenous melatonin on plant height $(A)$ and stem diameter $(B)$ of cucumber seedlings under chilling stress. Means \pm SEs, $n=5$. Different letters indicate significant differences according to Duncan's multiple range test $(P<0.05)$. 
with chilling, net photosynthetic rates of the leaves of the melatonin-treated plants were higher by $25.5 \%$ on day 2 and $41.4 \%$ on day 6 , respectively.

We also measured the chlorophyll fluorescence parameters. Under un-chilled conditions, $\mathrm{F}_{\mathrm{v}} / \mathrm{F}_{\mathrm{m}}$ remained at about 0.8 with or without melatonin (Fig. 3). Chilling led to a sharp decline of $\mathrm{F}_{\mathrm{v}} / \mathrm{F}_{\mathrm{m}}$. On day 8 of chilling, $\mathrm{F}_{\mathrm{v}} / \mathrm{F}_{\mathrm{m}}$ decreased from 0.80 to 0.63 . However, the melatonin greatly alleviated and delayed the decline in $\mathrm{F}_{\mathrm{v}} / \mathrm{F}_{\mathrm{m}}$ caused by chilling. Different from the rapid decline in $\mathrm{F}_{\mathrm{v}} / \mathrm{F}_{\mathrm{m}}$ in the chilled plants, after the start of chilling, melatonin slowed the slower decline of $F_{v} / F_{m}$ after chilling up to day 6 but then $F_{v} / F_{m}$ declined rapidly by day 8 . Compared with chilling with no melatonin, the value of $F_{v} / F_{m}$ of chilled seedlings with melatonin was higher 3.8 to $12.1 \%$ during the chilling period.

Chilling also led to a dramatic decrease in qP. Compared to the initial value of the chilling group on

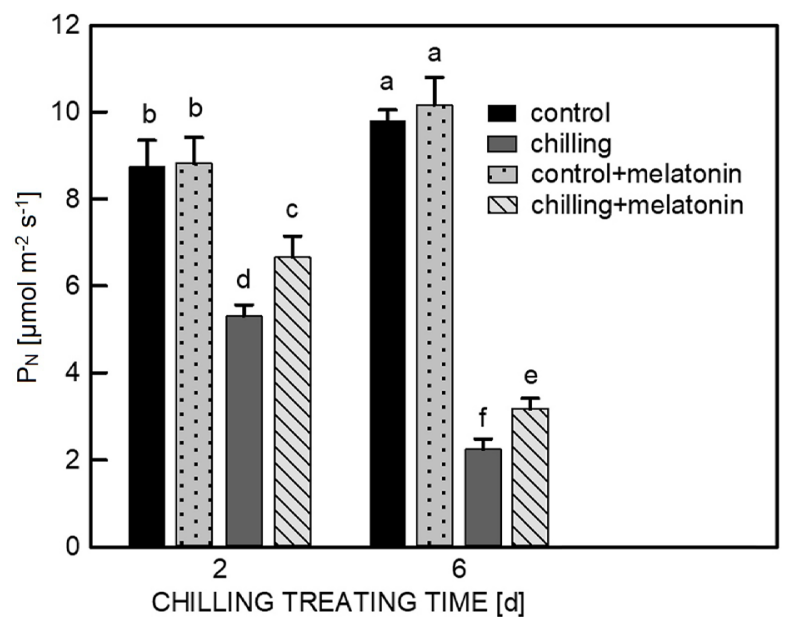

Fig. 2. Effects of exogenous melatonin on net photosynthesis rate $\left(\mathrm{P}_{\mathrm{N}}\right)$ in cucumber seedlings under chilling stress. Means $\pm \mathrm{SEs}$, $n=3$. Different letters indicate significant differences according to Duncan's multiple range test $(P<0.05)$.

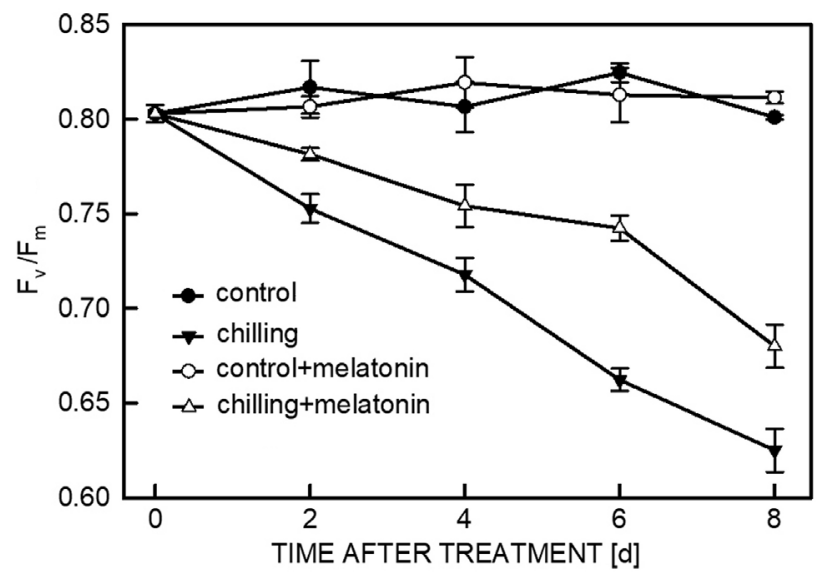

Fig. 3. Effects of exogenous melatonin on a variable to maximum fluorescence ratio $\left(\mathrm{F}_{\mathrm{v}} / \mathrm{F}_{\mathrm{m}}\right)$ which characterize maximum quantum efficiency of PS II in cucumber seedlings under chilling stress. Means \pm SEs, $n=3$. Different letters indicate significant differences according to Duncan's multiple range test $(P<0.05)$. day 0 , the decrease on day 2 was $16.6 \%$, and by $8 \mathrm{~d}$, the decrease reached $62.8 \%$ (Fig. $4 A$ ). The pretreatment with melatonin somewhat mitigated the decline caused by chilling. The $\mathrm{qP}$ of pretreated plants with melatonin was higher by 10.1 to $16.8 \%$ than that without melatonin from day 2 to day 8 .

Under normal temperatures, NPQ remained around 0.32 with minor fluctuations. There was no significant difference between seedlings irrigated with water or those with water+melatonin. After chilling, the NPQ value of seedlings with melatonin increased significantly, reaching 0.39 on day 2 and reached a plateau at around 0.53 thereafter (Fig. $4 B$ ). However, the NPQ of seedings without melatonin under chilling did not increase until day 4 , then reached a plateau at around 0.4 .

In response to chilling, the three xanthophyll pigments, violaxanthin (V), antheraxanthin (A), and zeaxanthin (Z) increased by $36.7,243.9$, and $82.5 \%$, respectively, compared with the control (Table 1). Chilling also induced a significant increase in the total $\mathrm{V}+\mathrm{A}+\mathrm{Z}$ pool and the de-epoxidation ratio of the xanthophyll cycle $[(A+Z) /$ $(\mathrm{V}+\mathrm{A}+\mathrm{Z})]$. Compared with the control, the increases in these values were 90.13 and $29.6 \%$, respectively. The melatonin treatment clearly affected the components of the xanthophyll cycle and $(\mathrm{A}+\mathrm{Z}) /(\mathrm{V}+\mathrm{A}+\mathrm{Z})$ but had no significant effect on the total $\mathrm{V}+\mathrm{A}+\mathrm{Z}$ pool after chilling. Compared with chilling, melatonin+chilling decreased the contents of $\mathrm{V}$ and $\mathrm{A}$ by 22.5 and $18.91 \%$, respectively, but increased the content of $\mathrm{Z}$ and the ratio of $(\mathrm{A}+\mathrm{Z}) /(\mathrm{V}+\mathrm{A}+\mathrm{Z})$ by 47.6 and $14.4 \%$, respectively.

As shown in Fig. 5, the expression of the violaxanthin de-epoxidase gene ( $C S V D E)$ began to decline after chilling, decreasing most by 6 and $12 \mathrm{~h}$, the expression then being only 13.2 and $11.0 \%$, respectively, of that when chilling started. Compared with the water control, under chilling the melatonin treatment up-regulated $C s V D E$ 8.8-fold at $6 \mathrm{~h}$ and down-regulated it by $76,8 \%$. at $24 \mathrm{~h}$. Expression of the zeaxanthin cyclase gene $(C S Z E)$ did not change significantly during chilling except at $12 \mathrm{~h}$ when it was 2.54-fold higher than at the start of chilling. This increase was completely inhibited by the melatonin treatment.

The partitioning of absorbed excitation energy in PS II was also investigated. Levels of Y(II), Y(NPQ), and $\mathrm{Y}(\mathrm{NO})$ stayed between $0.53 \sim 0.59,0.10 \sim 0.11$ and $0.31 \sim 035$, respectively. Also, there were no significant differences between the values with and without melatonin under non-chilling conditions (Fig. 6). Chilling induced a dramatic decline in $\mathrm{Y}(\mathrm{II})$, with the decline reaching $75.9 \%$ by day 8 compared with the prechilling value. However, the decline under chilling was clearly reduced by melatonin, with values of Y(II) being $14.6 \sim 32.1 \%$ higher than in the water controls. Under chilling stress, Y(NPQ) increased slightly by day 2 and then climbed more quickly. By day 8, Y(NPQ) was 2.54-fold higher than in the controls. Melatonin treatment clearly delayed the rise during chilling after day 2. Levels of Y(NO) increased rapidly by day 4 and stayed high in the last two days of chilling. Melatonin significantly suppressed and delayed the rise. With melatonin, Y(NO) hardly changed from the initial value until day 4 . It then rose significantly 
but was still $9.3 \sim 14.7 \%$ lower than in the chillings in the last four days.

\section{Discussion}

Cucumber is extremely sensitive to chilling ( $\mathrm{Xu}$ et al. 2008). Chilling delays the growth of cucumber seedlings but this effect is mitigated by melatonin (Fig. 1). The photosynthetic rate is a good indicator of cucumber's response to chilling (Kalisz et al. 2016, Gan et al. 2019). To quantify the level of protection offered by melatonin, we monitored the photosynthetic rate on day 2 and day 6 after chilling was imposed. The results show that chilling led to a sharp decline in the photosynthetic rate. The photosynthetic rates on day 2 and day 6 were only $60.7 \%$ and $22.9 \%$ of the controls, respectively (Fig. 2). However, this decline can be significantly slowed by melatonin. Similar photosynthesis-preserving effects of melatonin have been reported in previous studies, including in response to water stress, salinity stress, and drought stress (Li et al. 2012, Zhang et al. 2012, Liu et al. 2015, Siddiqui et al. 2019). Consistent with these studies, our results confirm the protective role of melatonin in chilling stress.

The mitigating effect of melatonin on photoinhibition suggests that melatonin may moderate the absorption and utilization of radiation energy in PS II. To gain further insights, we monitored the chlorophyll fluorescence parameters. We found that chilling caused a significant decrease in $\mathrm{F}_{\mathrm{v}} / \mathrm{F}_{\mathrm{m}}$ but this decrease was mitigated by melatonin (Fig. 3). The $F_{v} / F_{m}$ reflects the maximum potential of radiation energy utilization by PS II (Kusaba et al. 2007, Baker 2008). It means that in cucumber seedlings, melatonin can help maintain the potential for radiation energy utilization by PS II. Similar findings have been reported in Malus hupehensis under salt stress, in wheat under boron stress, and in tomato under chilling stress (Li et al. 2012, Al-Huqail et al. 2020, Wang et al. 2020).

Chilling decreased $\mathrm{qP}$ but increased NPQ in our cucumber seedlings (Fig. 4). Being related to the proportion of radiation energy absorbed by PS II antenna pigments for photochemical electron transfer, $\mathrm{qP}$ reflects the openness of PS II reaction centers (Butler 1978, Lavergne and Trissl 1995). The effect of melatonin on the decline in $\mathrm{qP}$ on chilling indicates that melatonin contributes to the

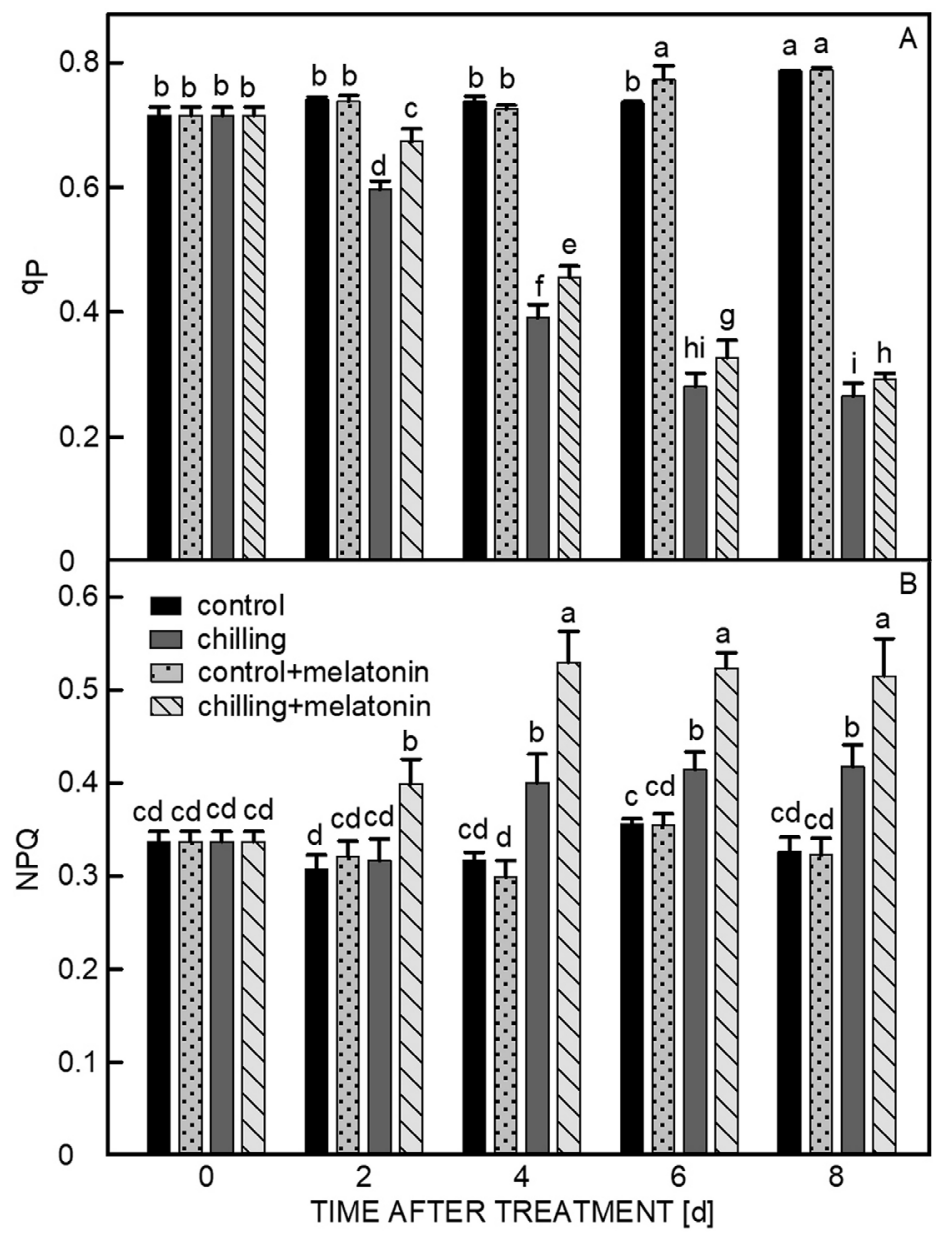

Fig. 4. Effects of exogenous melatonin on photochemical quenching $(\mathrm{qP})(A)$ and non-photochemical quenching $(\mathrm{NPQ})(B)$ in cucumber seedlings under chilling stress. Means \pm SEs, $n=3$. Different letters indicate significant differences according to Duncan's multiple range test $(P<0.05)$. 
Table 1. Effects of exogenous melatonin on xanthophyll cycle components in cucumber seedlings under chilling stress. Means \pm SEs, $n=3$. Different letters indicate significant differences according to Duncan's multiple range test $(P<0.05)$.

\begin{tabular}{|c|c|c|c|c|}
\hline Treatments & Control & Control + melatonin & Chilling & Chilling + melatonin \\
\hline 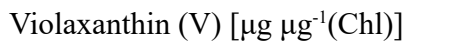 & $0.5126 \pm 0.0111 \mathrm{c}$ & $0.5009 \pm 0.0131 \mathrm{c}$ & $0.7012 \pm 0.0162 \mathrm{a}$ & $0.5432 \pm 0.0175 b$ \\
\hline Antheraxanthin (A) $\left[\mu \mathrm{g} \mu \mathrm{g}^{-1}(\mathrm{Chl})\right]$ & $0.1822 \pm 0.0148 \mathrm{c}$ & $0.1658 \pm 0.0141 \mathrm{c}$ & $0.6472 \pm 0.0229 \mathrm{a}$ & $0.5248 \pm 0.0479 b$ \\
\hline Zeaxanthin $(\mathrm{Z})\left[\mu \mathrm{g} \mu \mathrm{g}^{-1}(\mathrm{Chl})\right]$ & $0.3040 \pm 0.0240 \mathrm{c}$ & $0.3118 \pm 0.0222 \mathrm{c}$ & $0.5548 \pm 0.0466 \mathrm{~b}$ & $0.8188 \pm 0.0223 \mathrm{a}$ \\
\hline $\mathrm{V}+\mathrm{A}+\mathrm{Z}\left[\mu \mathrm{g} \mu \mathrm{g}^{-1}(\mathrm{Chl})\right]$ & $0.9987 \pm 0.0349 b$ & $0.9784 \pm 0.0340 \mathrm{~b}$ & $1.8988 \pm 0.0436 \mathrm{a}$ & $1.8868 \pm 0.0350 \mathrm{a}$ \\
\hline$(\mathrm{A}+\mathrm{Z}) /(\mathrm{V}+\mathrm{A}+\mathrm{Z})$ & $0.4865 \pm 0.0152 \mathrm{c}$ & $0.4879 \pm 0.0092 \mathrm{c}$ & $0.6304 \pm 0.1680 \mathrm{~b}$ & $0.7210 \pm 0.0129 \mathrm{a}$ \\
\hline
\end{tabular}

photochemical electron transfer in the photosystem, in such a way as to help maintain normal rates of photosynthesis. This is consistent with the findings in the determination of $\mathrm{P}_{\mathrm{N}}$ (Fig. 2) and those of a previous study in which melatonin regulates the distribution of electron flow in PS II (Zhao et al. 2016). NPQ is related to the dissipation of excessive excitation energy in the photosystem and thus reflects the mitigation effects on photoinhibition (Baker 2008). The effects of NPQ induced by chilling were further enhanced by melatonin. This supports the idea that melatonin increases the rate of dissipation of excessive excitation energy in the photosystem.

The xanthophyll cycle is involved in NPQ (Kromdijk et al. 2016). The components of the xanthophyll cycle were detected on day 4 of chilling. The results show that chilling can increase the content of $\mathrm{V}, \mathrm{A}, \mathrm{Z}$, and $(\mathrm{A}+\mathrm{Z}) /(\mathrm{V}+\mathrm{A}+\mathrm{Z})$ ratio (Table 1). This is because the de-epoxidation of $\mathrm{V}$ to $\mathrm{A}$ and then to $\mathrm{Z}$ will be excited when plants suffer from stress (Goss and Jakob 2010).

Although there is no consensus on the mechanism of excessive radiation energy dissipation by the xanthophyll cycle, two hypotheses have been developed: 1 ) the direct

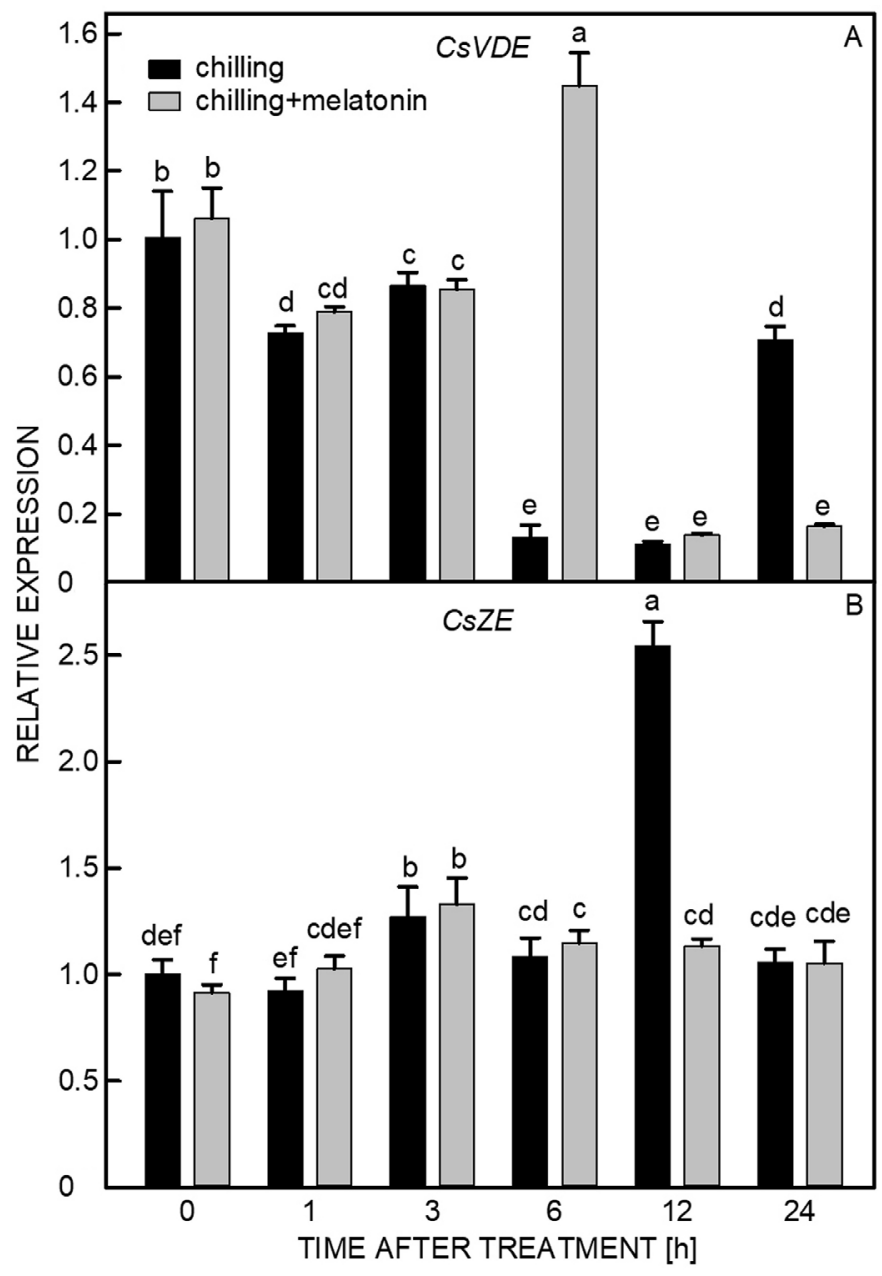

Fig. 5. Effects of exogenous melatonin on the relative expression of genes involving the xanthophyll cycle in cucumber seedlings under chilling stress $(0-24 \mathrm{~h}) . A$ - violaxanthin de-epoxidase gene $(C s V D E), B$ - zeaxanthin cyclase gene $(C s Z E)$. Means $\pm \mathrm{SEs}, n=3$. Different letters indicate significant differences according to Duncan's multiple range test $(P<0.05)$. 
quenching hypothesis which says that $\mathrm{Z}$ or $\mathrm{A}$ can receive the energy transferred by excited chlorophyll directly, and then dissipate it in the form of thermal energy; and 2) the indirect quenching hypothesis which says that the transition from $\mathrm{V}$ to $\mathrm{A}$ to $\mathrm{Z}$ leads to change in the $\mathrm{pH}$ gradient across thylakoids, which in turn leads to a conformation transition of PS II light-harvesting complex from a light-focusing state to an energy-dissipation state (Gilmore 1997). No matter which hypothesis prevails, the increases in $\mathrm{V}, \mathrm{A}$, $\mathrm{Z}$ content, and $(\mathrm{A}+\mathrm{Z}) / \mathrm{V}$ ratio are overall beneficial to the dissipation of excess energy in PS II. The de-epoxidation of $\mathrm{V}$ to $\mathrm{A}$ and then to $\mathrm{Z}$ is catalyzed by violaxanthin deepoxidase (VDE) while the epoxidation of $\mathrm{Z}$ to $\mathrm{A}$ and to $\mathrm{V}$ is catalyzed by zeaxanthin cyclase (ZE) in the xanthophyll cycle (Jahns and Holzwarth 2011). The gene expression analysis shows that melatonin can promote the expression of CsVDE but inhibit the expression of CsZE (Fig. 5) which is consistent with the observation that melatonin increases the content of $\mathrm{Z}$ and $(\mathrm{A}+\mathrm{Z}) / \mathrm{V}$ ratio in cucumber seedlings under chilling. These findings show that melatonin can regulate the xanthophyll cycle in cucumber seedlings to increase the dissipation of excessive excitation energy.

To confirm the role of melatonin in changing the absorbed excitation energy in PS II, the partitioning of absorbed excitation energy in PS II was also investigated. The consumption of radiation energy absorbed by plant PS II can be divided into three parts: 1) one part converted into chemical energy to provide energy for biochemical reactions such as photosynthesis and photorespiration and the ratio of this energy is represented as Y(II);2) the second part is dissipated in the form of chlorophyll fluorescence or non-radiative attenuation and this proportion is represented as $\mathrm{Y}(\mathrm{NO})$, and 3$)$ the third part is dissipated in the form of heat. $\mathrm{Y}(\mathrm{NO})+\mathrm{Y}(\mathrm{NPQ})+\mathrm{Y}(\mathrm{II})=1$. The values of them all changed during chilling (Fig. 6; Gilmore 1997, Hendrickson et al. 2004, Karashima et al. 2009). The energy dissipated by the xanthophyll cycle belongs to the category of Y (NPQ) (Kromdijk et al. 2016). In this study with cucumber seedlings, chilling affected the utilization of radiation energy, resulting in a marked decrease in Y (II), while melatonin minimized the decrease of Y (II). This finding is consistent with the effect of melatonin on $\mathrm{qP}$, indicating that melatonin is indeed involved in the maintenance of physiological processes such as photosynthesis. In cucumber seedlings, chilling also led to rises in $\mathrm{Y}(\mathrm{NO})$ and $\mathrm{Y}(\mathrm{NPQ})$, while melatonin further increased Y(NPQ) and decreased Y(NO) (Fig. 6). Considering the finding that melatonin can increase the NPQ of cucumber seedlings under chilling, we suggest melatonin can regulate energy dissipation.

\section{Conclusions}

Melatonin mitigates photoinhibition in cucumber seedlings exposed to chilling. The mechanism (Fig. 1 Suppl.) seems

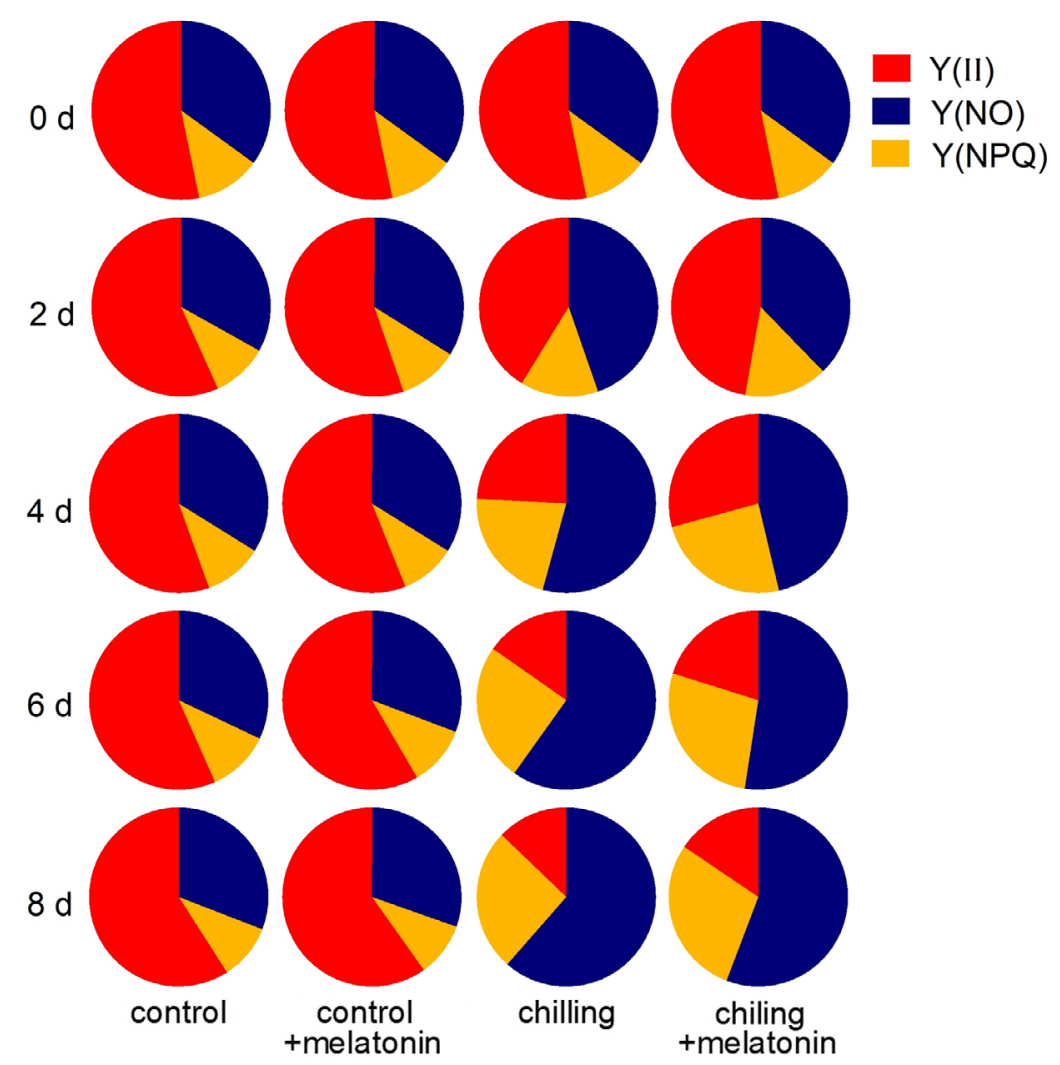

Fig. 6. Effects of exogenous melatonin on the partitioning of absorbed excitation energy by PS II in cucumber seedlings under chilling stress. Y(II) - quantum yield of photochemical energy conversion in PS II; Y(NO) - quantum yield of non-regulated non-photochemical energy loss in PS II; Y(NPQ) - quantum yield of regulated non-photochemical energy loss in PS II. Means, $n=3$. 
to be: melatonin increases the expression of $C s V D E$ but inhibits the expression of $C s Z E$, resulting in acceleration of the de-epoxidation of the xanthophyll cycle and the consumption of excessive excitation energy. These contribute to the moderation of the distribution of absorbed excitation energy in PS II and better maintenance of the normal operations of the photosynthetic system.

\section{References}

Al-Huqail, A., Khan, M., Ali, H., Siddiqui, D.M.H., Al-Huqail, A., Al-Zuaibr, F., Al-Muwayhi, M., Marraiki, N., Al-Humaid, L.A.: Exogenous melatonin mitigates boron toxicity in wheat. - Ecotoxicol. Environ. Safety 201: 110822, 2020.

Allen, D.J., Ort, D.R.: Impacts of chilling temperatures on photosynthesis in warm-climate plants. - Trends Plant Sci. 6: 36-42, 2001.

Arms, E.M., Bloom, A.J., St. Clair, D.A.: High-resolution mapping of a major effect QTL from wild tomato Solanum habrochaites that influences water relations under root chilling. - Theor. appl. Genet. 128: 1713-1724, 2015.

Baker, N.R.: Chlorophyll fluorescence: a probe of photosynthesis in vivo. - Annu. Rev. Plant Biol. 59: 89-113, 2008.

Butler, W.L.: Energy distribution in the photochemical apparatus of photosynthesis. - Annu. Rev. Plant Biol. 29: 345-378, 1978.

Cooper, J.W., Hu, Y., Beyyoudh, L., Yildiz Dasgan, H., Kunert, K., Beveridge, C.A., Foyer, C.H.: Strigolactones positively regulate chilling tolerance in pea and in Arabidopsis. - Plant Cell Physiol. 41: 1298-1310, 2018.

Gan, P., Liu, F., Li, R., Wang, S., Luo, J.: Molecular sciences chloroplasts-beyond energy capture and carbon fixation: tuning of photosynthesis in response to chilling stress. - Int. J. mol. Sci. 20: 5046-5060, 2019.

Gilmore, A.M.: Mechanistic aspects of xanthophyll cycledependent photoprotection in higher plant chloroplasts and leaves. - Physiol. Plant. 99: 197-209, 1997.

Goss, R., Jakob, T.: Regulation and function of xanthophyll cycle-dependent photoprotection in algae. - Photosynth. Res. 106: 103-122, 2010.

Heidarvand, L., Amiri, R.M.: What happens in plant molecular responses to cold stress? - Acta Physiol. Plant. 32: 419-431, 2010.

Hendrickson, L., Furbank, R.T., Chow, W.S.: A simple alternative approach to assessing the fate of absorbed light energy using chlorophyll fluorescence. - Photosynth. Res. 82: 73-81, 2004.

Hu, L., Xiang, L., Li, Z., Zhou, X., Zou, Z., Hu, X., Wu, K.: The photoprotective role of spermidine in tomato seedlings under salinity-alkalinity stress. - Plos ONE 9: e110855, 2014.

Hu, W.H., Wu, Y., Zeng, J.Z., He, L., Zeng, Q.M.: Chillinduced inhibition of photosynthesis was alleviated by 24-epibrassinolide pretreatment in cucumber during chilling and subsequent recovery. - Photosynthetica 48: 537-544, 2010.

Jahns, P., Holzwarth, A.: The role of the xanthophyll cycle and of lutein in photoprotection of photosystem II. - Biochim. biophys. Acta 1817: 182-193, 2011.

Kalisz, A., Jezdinský, A., Pokluda, R., Sękara, A., Grabowska, A., Gil, J.: Impacts of chilling on photosynthesis and chlorophyll pigment content in juvenile basil cultivars. - Hort. Environ. Biotechnol. 57: 330-339, 2016.

Karashima, Y., Talavera Perez, K., Everaerts, W., Janssens, A., Kwan, K., Vennekens, R., Nilius, B., Voets, T.: TRPA1 acts as a cold sensor in vitro and in vivo. - Proc. nat. Acad. Sci. USA 106: 1273-1278, 2009.
Kasamo, K., Kagita, F., Yamanishi, H., Sakaki, T.: Low temperature-induced changes in the thermotropic properties and fatty acid composition of the plasma membrane and tonoplast of cultured rice (Oryza sativa L.) cells. - Plant Cell Physiol. 33: 609-616, 1992.

Kaya, C., Okant, M., Ugurlar, F., Alyemeni, M.N., Ashraf, M., Ahmad, P.: Melatonin-mediated nitric oxide improves tolerance to cadmium toxicity by reducing oxidative stress in wheat plants. - Chemosphere 225: 627-638, 2019.

Klughammer, C., Schreiber, U.: Complementary PS II quantum yields calculated from simple fluorescence parameters measured by PAM fluorometry and the saturation pulse method. - PAN Appl. Notes 1: 27-35, 2008.

Kromdijk, J., Glowacka, K., Leonelli, L., Gabilly, S.T., Iwai, M., Niyogi, K.K., Long, S.P.: Improving photosynthesis and crop productivity by accelerating recovery from photoprotection. Science 354: 857-861, 2016.

Kusaba, M., Ito, H., Morita, R., Iida, S., Sato, Y., Fujimoto, M., Kawasaki, S., Tanaka, R., Hirochika, H., Nishimura, M.: Rice NON-YELLOW COLORING1 is involved in light-harvesting complex II and grana degradation during leaf senescence. Plant Cell 19: 1362-1375, 2007.

Lavergne, J., Trissl, H.W.: Theory of fluorescence induction in photosystem II: derivation of analytical expressions in a model including exciton-radical-pair equilibrium and restricted energy transfer between photosynthetic units. - Biophys. J. 68: 2474-2492, 1995

Li, C., Wang, P., Wei, Z., Liang, D., Ma, F.: The mitigation effects of exogenous melatonin on salinity-induced stress in Malus hupehensis. - J. Pineal Res. 53: 298-306, 2012.

Liu, J., Wang, W., Wang, L., Sun, Y.: Exogenous melatonin improves seedling health index and drought tolerance in tomato. - Plant Growth Regul. 77: 317-326, 2015.

López-Bernal, Á., García-Tejera, O., Vega, V.A., Hidalgo, J.C., Testi, L., Orgaz, F., Villalobos, F.J.: Using sap flow measurements to estimate net assimilation in olive trees under different irrigation regimes. - Irrig. Sci. 33: 357-366, 2015.

Pu, Y.-J., Cisse, E.H.M., Zhang, L.-J., Miao, L.-F., Nawaz, M., Yang, F.: Coupling exogenous melatonin with $\mathrm{Ca}^{2+}$ alleviated chilling stress in Dalbergia odorifera T. Chen. - Trees 2021: 1-14, 2021.

Siddiqui, M.H., Alamri, S., Al-Khaishany, M.Y., Khan, M.N., AlAmri, A., Ali, H.M., Alaraidh, I.A., Alsahli, A.A.: Exogenous melatonin counteracts $\mathrm{NaCl}$-induced damage by regulating the antioxidant system, proline and carbohydrates metabolism in tomato seedlings. - Int. J. mol. Sci. 20: 353, 2019.

Siddiqui, M.H., Alamri, S., Nasir Khan, M., Corpas, F.J., AlAmri, A.A., Alsubaie, Q.D., Ali, H.M., Kalaji, H.M., Ahmad, P.: Melatonin and calcium function synergistically to promote the resilience through ROS metabolism under arsenic-induced stress. - J. Hazard. Mater. 398: 122882, 2020.

Tuzet, A., Perrier, A., Leuning, R.: A coupled model of stomatal conductance, photosynthesis and transpiration. - Plant Cell Environ. 26: 1097-1116, 2003.

Wang, M., Zhang, S., Ding, F.: Melatonin mitigates chillinginduced oxidative stress and photosynthesis inhibition in tomato plants. - Antioxidants 9: 218, 2020.

Wang, M., Duan, S., Zhou, Z., Chen, S., Wang, D.: Foliar spraying of melatonin confers cadmium tolerance in Nicotiana tabacum L. - Ecotox. Environ. Safety 170: 68-76, 2019a.

Wang, P., Sun, X., Li, C., Wei, Z., Liang, D.: Long-term exogenous application of melatonin delays drought-induced leaf senescence in apple. - J. Pineal Res. 54: 292-302, 2012.

Wang, Y., Wang, G., Zheng, Y., Zheng, Y., Xu, S.: Polyamines are involved in chilling tolerance in tobacco (Nicotiana tabacum) seedlings. - Plant Growth Regul. 89: 153-166, 2019 b. 
Xu, P.L., Guo, Y.K., Bai, J.G., Shang, L., Wang, X.J.: Effects of long-term chilling on ultrastructure and antioxidant activity in leaves of two cucumber cultivars under low light. - Physiol. Plant. 132: 467-478, 2008.

Zhang, N., Zhao, B., Zhang, H.J., Weeda, S., Guo, Y.D.: Melatonin promotes water-stress tolerance, lateral root formation, and seed germination in cucumber (Cucumis sativus L.). - J. Pineal Res. 54: 15-23, 2012.

Zhang, Z., Jia, Y., Gao, H., Zhang, L., Li, H., Meng, Q.: Characterization of PSI recovery after chilling-induced photoinhibition in cucumber (Cucumis sativus L.) leaves. Planta 234: 883-889, 2011.

Zhang, Z., Liu, M., Gao, H., Jin, L., Li, Y., Li, Q., Ai, X.: Water status related root-to-shoot communication regulates the chilling tolerance of shoot in cucumber (Cucumis sativus L.) plants. - Sci. Rep. 5: 13094, 2015.

Zhao, H., Ye, L., Wang, Y., Zhou, X., Yang, J., Wang, J., Cao, K., Zou, Z.: Melatonin increases the chilling tolerance of chloroplast in cucumber seedlings by regulating photosynthetic electron flux and the ascorbate-glutathione cycle. - Front. Plant Sci. 7: 1814, 2016.

Zhao, H., Zhang, K., Zhou, X., Xi, L., Wang, Y., Xu, H., Pan, T., Zou, Z.: Melatonin alleviates chilling stress in cucumber seedlings by up-regulation of CsZat12 and modulation of polyamine and abscisic acid metabolism. - Sci Rep. 7: 4998, 2017.

Zou, J.N., Jin, X.J., Wang, Y.X. Effects of melatonin on photosynthesis and soybean seed growth during grain filling under drought stress. - Photosynthetica 57: 512-520, 2019. 